\title{
A New Class of Solvents for TRU Dissolution and Separation: Ionic Liquids
}

Progress Report - Project \# 81891

AWARD NO. DE-FG07-01ER63266

Period September 15, 2001 - September 14, 2004

Robin D. Rogers

Department of Chemistry and Center for Green Manufacturing,

The University of Alabama,

Tuscaloosa, AL 35487

\section{Contents}

Executive Summary

1. Examine $\mathrm{Cs}, \mathrm{Sr}, \mathrm{Tc}$, and TRU partitioning in Ionic Liquid/aqueous systems:

1.1 Development of Highly Selective Extraction Process for $\mathrm{Cs}^{+}$Based on Calixarenes.

1.2 IL/Aqueous Partitioning or TRU ions using CMPO/TBP Complexants

1.3 Cellulose supported CMPO-Resin Extractants

1.4 Partitioning to ILs containing the Ionizable Complexant Cyanex-272

1.5 Partitioning to ILs containing the Neutral Phosphine-Oxide Complexant, Cyanex923

1.6 Siderophore-based extractants

2. Develop new Ionic Liquids for TRU separations:

3. Study the speciation and coordination of TRU elements in both hydrophilic and hydrophobic ionic liquids:

3.1 Coordination of $\left[\mathrm{UO}_{2}\right]^{2+}$ in IL/CMPO systems

3.2 Coordination of $\mathrm{Am}^{3+}$ stand-ins, $\mathrm{Nd}^{3+}$ and $\mathrm{Eu}^{3+}$, in IL/Cyanex-272 systems

3.3 X-ray structure of a hexavalent dinuclear uranyl nitrate complex in a zwitteronic IL.

4. Investigate how aqueous phase composition affects the liquid/liquid partitioning behavior with particular emphasis on aqueous phases similar to those found in DOE related tank wastes:

5. Determine the stability of ionic liquids to thermolysis and radiolysis:

6. Investigate the unique heat transfer properties of ionic liquids for use in other processing steps:

6.1 Thermophysical Properties of ILs

6.2 Determination of Heat Capacities

7. Publications and Presentations at Meetings Acknowledging DOE support from the Current Project Period:

7.1 Refereed Publications

7.2 Thesis Completed

7.3 Presentations before National and International Meetings 


\section{Executive Summary}

Through the current EMSP funding, solvent extraction technologies based on liquid-liquid partitioning of TRU to an Ionic Liquid phase containing conventional complexants has been shown to be viable. The growing understanding of the role that the different components of an ionic liquid can have on the partitioning mechanism, and on the nature of the subsequent dissolved species indicates strongly that ionic liquids are not necessarily direct replacements for volatile or otherwise hazardous organic solvents. Separations and partitioning can be exceptionally complex with competing solvent extraction, cation, anion and sacrificial ion exchange mechanisms are all important, depending on the selection of components for formation of the ionic liquid phase, and that control of these competing mechanisms can be utilized to provide new, alternative separations schemes.

The major outcomes are:

1. Separations systems utilizing ILs as the extracting phase can be prepared. Mechanisms for the extraction are potentially much more complex that those with simple organic solvents as extracting phases. This arises from the potential for either, or, both cations and anions from the IL to contribute in the extraction processes. In contrast to organic extracting phases, ionic liquids can not necessarily be considered to be passive carrier fluids. Solvent extraction and cation, anion, or sacrificial ion exchange mechanisms have been observed, and the significance of each varies depending on the nature of the ionic liquid components and of the complexants used. Recognition and application of this knowledge allows potential control of the complexation and extraction mechanisms.

2. Speciation and metal ion coordination environments can be different in ionic liquids compared to systems with either aqueous or coordinating or non-coordinating organic solvents. Two systems have been studied in detail by uv/visible spectroscopy and by EXAFS, with CMPO and Cyanex-272 extractants. Different metal coordination geometries and numbers were observed with CMPO when compared to the equivalent system with dodecane as solvent, even though there was no evidence for the IL cation or anions participating in the metals first coordination shell. In contrast, the coordination of TRU elements with Cyanex-272 revealed comparable coordination environments in the IL and dodecane systems.

3. It has been recognized that 1,3-dialkylimidazolium-based ILs are unsuitable for study under caustic, high $\mathrm{pH}$, conditions a wider range of ILs with increased $\mathrm{pH}$ stability is needed. Significantly, while only a limited number of hydrophobic ILs are known that form biphases with water, we have demonstrated that with high ionic strength aqueous phases, such as are present in the HLW streams, a much wider range of ILs are capable of sustaining liquidliquid biphase formations, we term these salt-salt systems. these salt-salt biphase systems can be applied to extraction and separations processes. Notably, we have shown that $\left[\mathrm{TcO}_{4}\right]^{-}$ partitions to the organic IL phase of simple salt-salt biphasic systems such as these with distribution ratios between 100-800 in the absence of any additional extractants.

Detailed progress on the study of a "New Class of Solvents for TRU Dissolution and Separation: Ionic Liquids" is summarized under the headings of the major proposal objectives. 


\section{Examine $\mathrm{Cs}, \mathrm{Sr}$, Tc, and TRU partitioning in Ionic Liquid/aqueous systems:}

Ionic Liquids (ILs) are composed of organic cations and either organic or inorganic anions that remain liquid over a wide temperature range, including room temperature. IL characteristics can be dramatically adjusted (e.g., hydrophobic vs. hydrophilic) by changing the anion type or subtly altered by changing the length or number of alkyl groups appended to the cation. Changing alkyl chain lengths in the 1-alkyl-3-methylimidazolium cation, in combination with $\left[\mathrm{PF}_{6}\right]^{-}$and $\left[\mathrm{N}\left(\mathrm{SO}_{2} \mathrm{CF}_{3}\right)_{2}\right]^{-}$anions, produces hydrophobic IL with rheological properties suitable for their use in liquid/liquid separations. The usefulness of Ionic Liquids (ILs) as separations media was demonstrated several times early on for the removal of metal ions such as $\mathrm{Cs}^{+}, \mathrm{Sr}^{2+}$, and $\mathrm{Hg}^{2+}$ from aqueous solutions using extractant molecules. It was from the success of these initial studies that led to the conjecture that ILs, too, could be used for the removal of hazardous actinide ions and fission products from aqueous streams. Here, we present some of the important progress that has been made toward reaching the goals of the first EMSP proposal and that has laid the groundwork for the objectives of the renewal. The results presented here primarily focus on the use of traditional extractant molecules in IL/aqueous liquid/liquid separations systems.

\subsection{Development of Highly Selective Extraction Process for $\mathrm{Cs}^{+}$Based on Calixarenes.}

In collaboration with ORNL, we extended our investigation of the solvent extraction and ion exchange properties of ILs to the extraction of cesium ions. A lipophilic derivative of a calix[4]bis-crown-6, calix[4]arene-bis(tert-octylbenzo-crown-6) ("BOBCalixC6") as shown in Figure 1 was utilized as a cation acceptor. These studies were directed primarily toward acquiring an understanding of the mechanism of extraction in the complex IL solvents, and secondarily to determining if a Cs-removal technology utilizing ILs is possible. The cations of the ILs used in this work were 1-alkyl-3-methylimidazolium $\left(\mathrm{C}_{n}\right.$ - $\left.\operatorname{mim}^{+}\right)$, where $\mathrm{C}_{n}=$ ethyl, butyl, hexyl, and octyl. The anion is bis[(trifluoromethyl)sulfonyl]amide $\left(\mathrm{NTf}_{2}{ }^{-}\right)$.

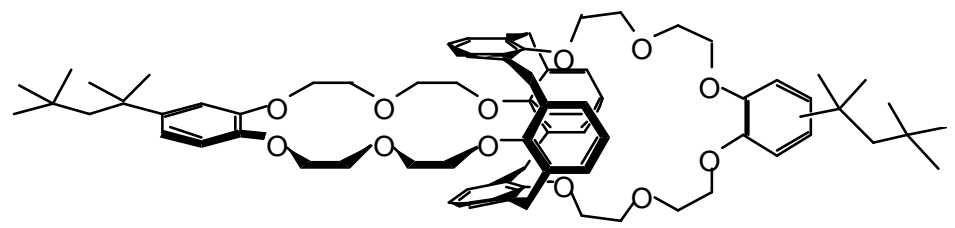

Figure 1. Structure of BOBCalixC6

The $D_{\mathrm{Cs}}$ values of the plain ILs in the absence of an extractant are very low. The small amount of $\mathrm{Cs}^{+}$which does partition into the ILs correlates with the observed hydrophobicities of the IL organic cations. The hydrophobicity is also inversely related to the solubility of the corresponding 1-alkyl-3-methylimidazolium cation $\left(\left[\mathrm{C}_{\mathrm{n}} \mathrm{mim}\right]^{+}\right)$in the aqueous phase, and thus its ion-exchange capability. Accordingly, the selectivity of this solvent is dominated by the hydrophobicity of the metal ions extracted (i.e., their Hofmeister selectivity). The solubilities of BOBCalixC6 in the ILs are quite high, even though this complexant was designed specifically for use in an organic extracting phase. As seen in Table 1, the distribution coefficients $\left(D_{\mathrm{Cs}}\right)$ of $\mathrm{Cs}^{+}$from water to IL with BOBCalixC6 strongly depend on the concentration of BOBCalixC6 in the ILs and increase with the concentration of the extractant. This observation is very similar to 
that noted in the extraction of $\mathrm{Sr}^{2+}$ with cis-dicyclohexano-18-crown-6 (DCH18C6) in ILs, indicating that the complexation of $\mathrm{Cs}^{+}$plays a key role in the partitioning processes.

\subsection{IL/Aqueous Partitioning or TRU ions using CMPO/TBP Complexants}

Actinides exhibit significant partitioning to these ILs from aqueous solutions with the addition of the extractant octyl(phenyl)- $N, N$-diisobutylcarbamoylmethyl phosphine oxide (CMPO, Figure 2) to the IL. Ionic liquids can thus, be considered for actinide chemistry as a new class of materials with adjustable solvent characteristics, unique properties, and the potential for enhancing the principles of "green" chemistry in various chemical processes.

We have investigated CMPO, enhanced with TBP, as an actinide extractant in an IL-based separations system utilizing 1-butyl-3-methylimdazolium hexafluorophosphate, $\left[\mathrm{C}_{4} \mathrm{mim}\right]\left[\mathrm{PF}_{6}\right]$. At low $\mathrm{HNO}_{3}$ concentrations, the distribution ratios or $\mathrm{Pu}^{4+}, \mathrm{Th}^{4+}, \mathrm{Am}^{3+}$, and $\mathrm{UO}_{2}{ }^{2+}$ are substantially enhanced as compared to those in dodecane, although the difference is less pronounced at higher concentrations (Figure 3). The addition of TBP to the IL causes an even further enhancement of distribution ratios compared to CMPO alone.

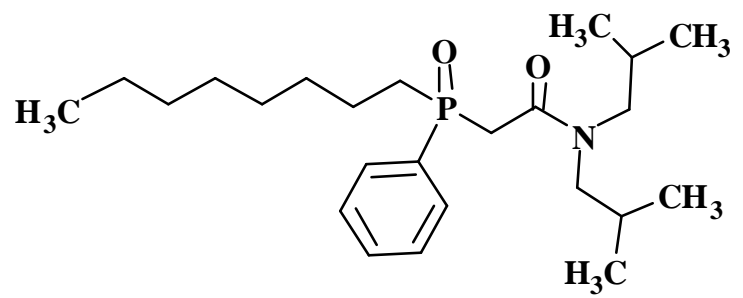

Figure 2. Structure of $C M P O$
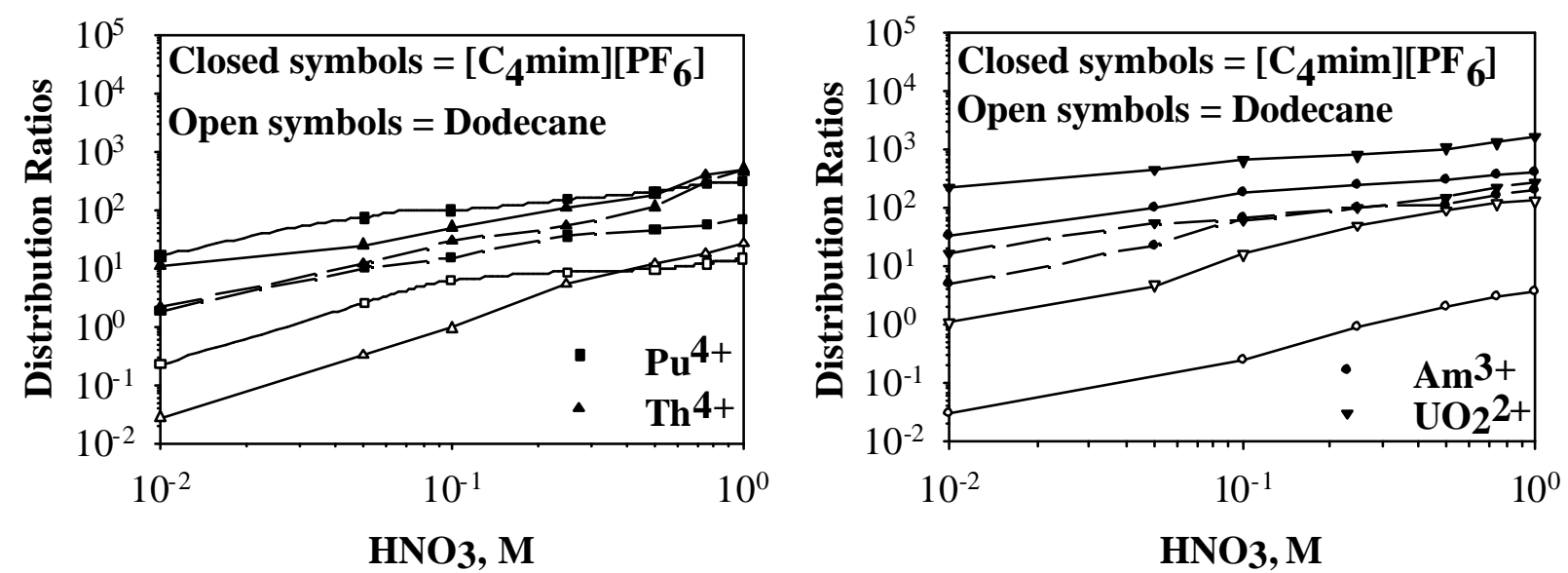

Figure 3 Distribution ratios for $\mathrm{Pu}^{4+}, \mathrm{Th}^{4+}, \mathrm{Am}^{3+}$, and $\mathrm{UO}_{2}{ }^{2+}$ in $\left[\mathrm{C}_{4} \mathrm{mim}\right]\left[\mathrm{PF}_{6}\right] /$ aqueous (solid symbols) or dodecane/aqueous (open symbols) liquid/liquid systems. The extracting phase is either 0.1M CMPO (dashed line) or 0.1M CMPO/1M TBP (solid line).

\subsection{Cellulose supported CMPO-Resin Extractants}

The preparation of novel cellulose supported complexents immobilized on biorenewable supports using a novel ionic liquid based dissolution and casting process was explored, building on the novel discovery that the IL, 1-butyl-3-methylimidazolium chloride, is an effective solvent 
for cellulose dissolution and processing. The actinide complexant (complexing agent), octyl(phenyl)- $N, N$-diisobutylcarbamoylmethyl-phosphine oxide, or CMPO can be incorporated into a reconstituted cellulose matrix to provide a solid supported metal extractant resin. The distribution of $\mathrm{Am}^{3+}, \mathrm{Pu}^{4+}$, and $\left[\mathrm{UO}_{2}\right]^{2+}$ between aqueous nitric acid solutions and modified cellulose materials impregnated with CMPO was studied in relation to the aqueous phase acidity and extractant content in the solid phase. The presence of CMPO was confirmed by enhanced distribution ratios (Figure 4). Systems were not optimized with respect to support structure or size of the extractant beads, but shows the potential $\mathrm{b}$ prepare new solid-supported TRUcomplexant resins.

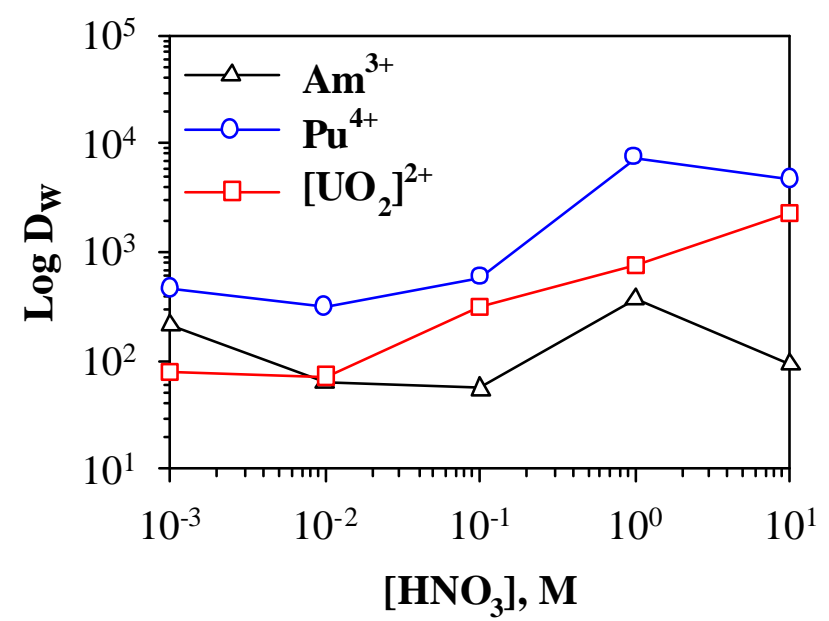

Figure 4. Uptake distributions of $\mathrm{Am}^{3+}, \mathrm{Pu}^{4+}$, and $\left[\mathrm{UO}_{2}\right]^{2+}$ tracers to CMPO impregnated solid cellulose extractant.

\subsection{Partitioning to ILs containing the Ionizable Complexant Cyanex-272}

The suite of Cyanex ${ }^{\circledR}$ complexants, distributed by Cytec, Inc., are phosphorus-based materials that have primary uses in metal extraction and separations. The use of Cyanex extractants for lanthanide and actinide complexation and separation has also been investigated, excellent extractive abilities for actinide ions with a range of valencies. Cyanex-272, or bis(2,4,4-trimethylpentyl)phosphinic acid, is an ionizable complexant that is an effective extractant for transition metals, and is used commercially for primary separation of Co and $\mathrm{Ni}$.

Partitioning of $\mathrm{Am}^{3+}$ and $\left[\mathrm{UO}_{2}\right]^{2+}$ between aqueous acidic solutions and the ionic liquid, 1-decyl-3-methylimidazolium bis(trifluoromethanesulfonyl)imide, using Cyanex-272 as an extractant has been investigated and compared to the analogous liquid/liquid system using dodecane as the extractant phase. Comparable distribution ratios, and ligand dependencies were found for both the IL and dodecane extracting phase systems. Data for $\mathrm{Am}^{4+}$ is shown in figure 5 , with the ligand dependency in figure 6 . Studies with $\left[\mathrm{UO}_{2}\right]^{2+}$ partitioning are shown in Figure 7. Leaching and solubility of the imidazolium cation from the ionic liquid to the aqueous phase as a function of nitric acid $\mathrm{pH}$ has been measured and does not appear to be a significant contributing factor to the observed metal ion distribution coefficients.

In addition, the extraction mechanism as elucidated from the distribution trends appears to be similar for both, going from ion exchange at low $\mathrm{HNO}_{3}$ concentrations to solvent extraction at high concentrations. 
Cyanex-272 is an ionizable complexant; the role of the ionized proton, as a sacrificial cation exchanger for metal ions, and changes in the IL composition are currently under study. The initial investigations of the coordination and metal complex environments by uv/vis spectroscopy and EXAFS, for $\left[\mathrm{UO}_{2}\right]^{2+}$ and $\mathrm{Eu}^{3+}$ and $\mathrm{Nd}^{3+}$ systems, as stand-ins for $\mathrm{Am}^{3+}$ are discussed below in section III.

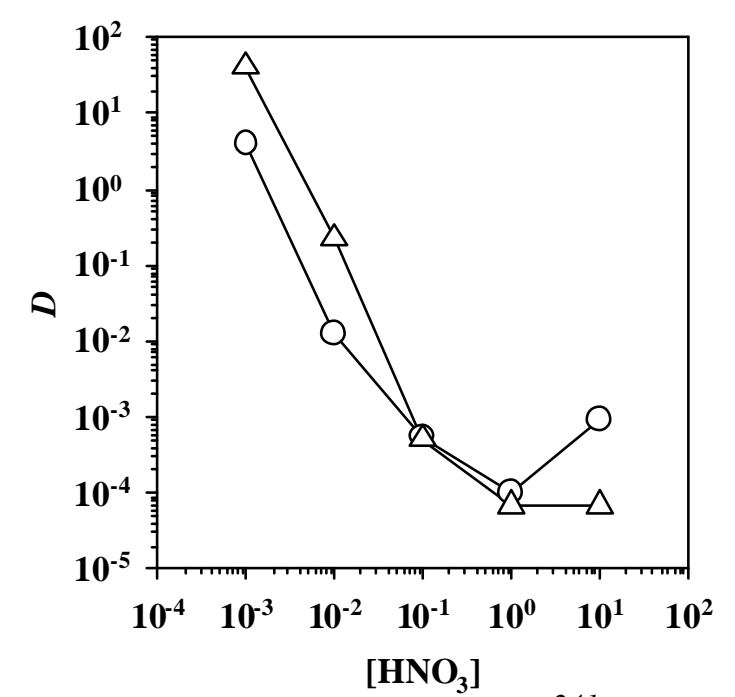

Figure 5. Distribution Ratios for ${ }^{241}$ Am in 0.1 $M$ Cyanex-272 vs. $\left[\mathrm{HNO}_{3}\right]$. Dodecane, [C $\left.\mathrm{C}_{10 \operatorname{mimTf}} \mathrm{N}\right]$

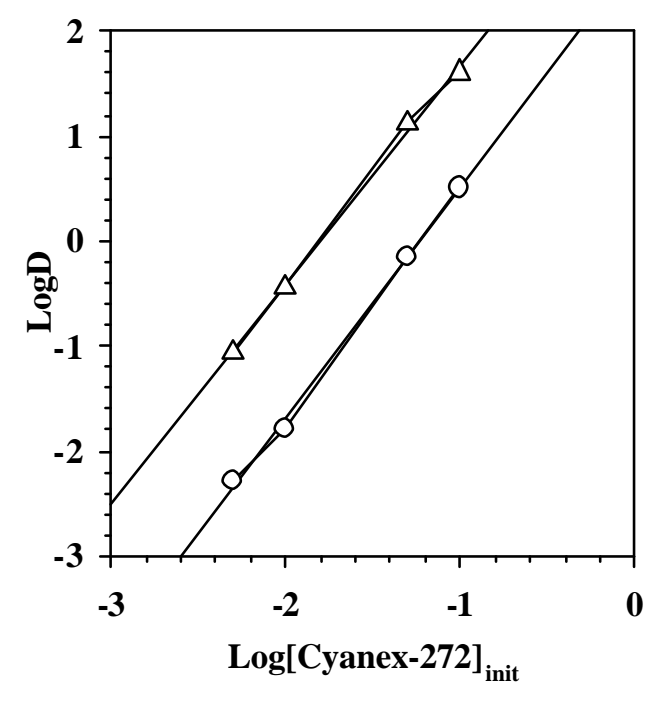

Figure 6. Ligand Dependency for ${ }^{241} \mathrm{Am}$ in in $\left[C_{10 \mathrm{mim}}\right]\left[\mathrm{NTf}_{2}\right]($, slope $=2.19)$ and dodecane ( , slope $=2.09)$ from $0.001 \mathrm{M}$ $\mathrm{HNO}_{3}$.

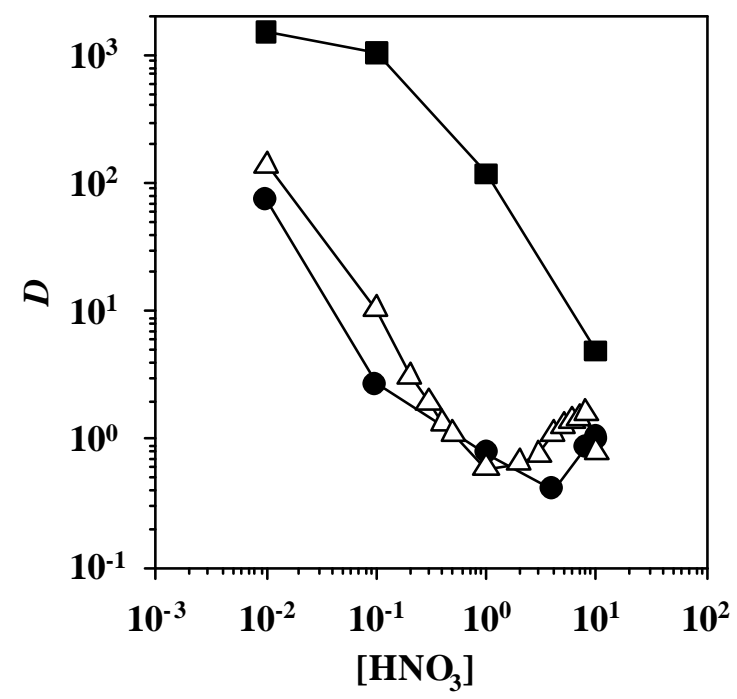

Figure 7 Uranyl distribution ratios for $0.005 \mathrm{M}$ Cyanex-272 in [C lomim] $_{\left.10 T f_{2}\right]}$ (?), $0.005 \mathrm{M}$ Cyanex-272 in dodecane (?), and $0.1 \mathrm{M}$ Cyanex-272 in [ $\mathrm{C}_{10 \mathrm{mim}}$ [ $\left[\mathrm{NTf}_{2}\right]$ (1) ) versus [ $\left.\mathrm{HNO}_{3}\right]$.

\subsection{Partitioning to ILs containing the Neutral Phosphine-Oxide Complexant, Cyanex- 923}

Cyanex-923 is a neutral extractant that is a mixture of tri-alkyl-phosphine oxides of varying chain lengths (hexyl- and octyl-) and has been studied as an extractant for lanthanide and 
actinides in traditional molecular solvents. Partitioning studies with Cyanex-923 in the hydrophobic IL $\left(\left[\mathrm{C}_{10} \mathrm{mim}\right]\left[\left(\mathrm{SO}_{2} \mathrm{CF}_{3}\right)_{2} \mathrm{~N}\right]\right)$, gave results comparable to those in dodecane. Distribution ratio measurements for $\left[\mathrm{UO}_{2}\right]^{2+}$ and $\mathrm{Pu}^{4+}$ (Figure 8) showed little acid dependency $\left(\mathrm{HNO}_{3}\right)$ for either species. In contrast, strong acid dependency was found in both the IL and dodecane systems for the trivalent actinide $\mathrm{Am}^{3+}$ (Figure 9). Ligand dependency studies seem to support 1:1 metalto-ligand binding for $\mathrm{Pu}^{4+}$, but significantly different binding ratios for $\mathrm{UO}_{2}{ }^{2+}$ and $\mathrm{Am}^{3+}$, indicating that ILs can provide coordination environments wholly different from molecular solvents.

Due to the high distribution ratios for $\mathrm{Pu}^{4+}$ and $\mathrm{UO}_{2}{ }^{2+}$ metals ions and lack of acid dependency, stripping studies of $\mathrm{Pu}^{4+}$ were performed with the oxalate anion. Oxalate has been used traditionally as a stripping agent due to its high affinity for tetravalent actinides such as plutonium. The stripping of $\mathrm{Pu}^{4+}$ from Cyanex-923 in dodecane (85\%) was more efficient that in the IL (70\%), although conditions were not optimized.

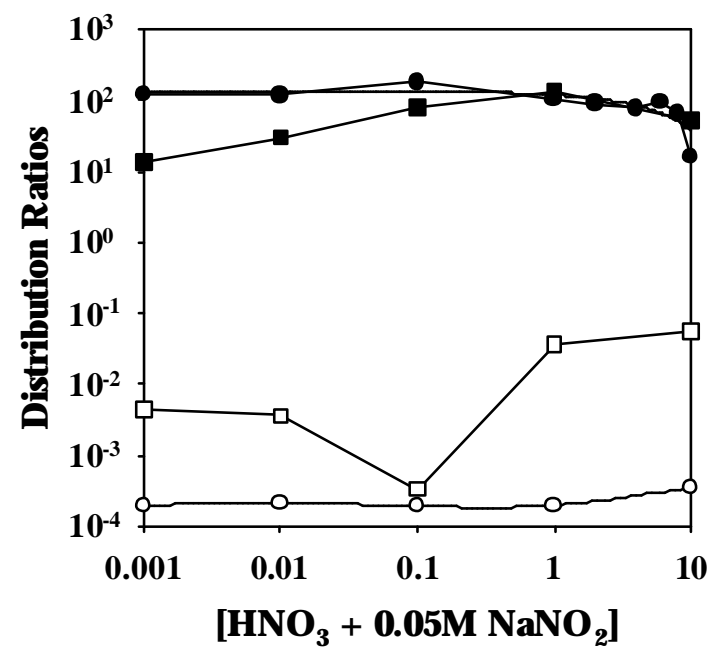

Figure 8 Distribution of $\mathrm{Pu}^{4+}$ by $0.10 \mathrm{M}$ Cyanex-923 in [C $\mathrm{C}_{10 \mathrm{mim}}\left[\mathrm{Tf}_{2} \mathrm{~N}\right]$ (?) and $0.10 \mathrm{M}$ Cyanex-923 in dodcane ( $(1)$ ), compared to the corresponding blanks (open symbols) containing no extractant.

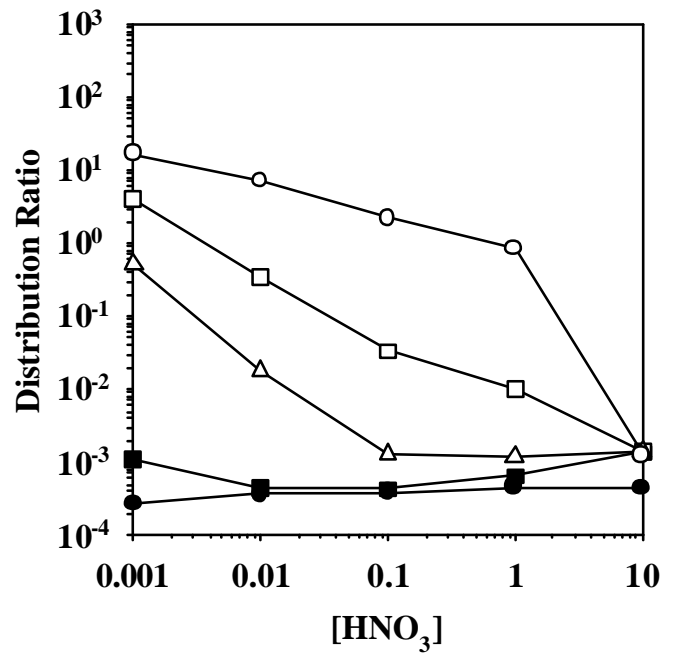

Figure 9. Distribution of $\mathrm{Am}^{3+}$ with $0.1 \mathrm{M}$

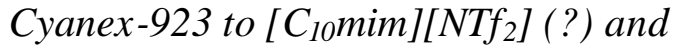
dodecane (?) from aqueous nitric acid compared to blanks with no extractant (closed symbols) and $0.05 \mathrm{M}$ Cyanex-923 in

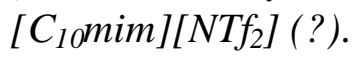

\subsection{Siderophore-based extractants}

Siderophores are molecules produced by bacteria to bind $\mathrm{Fe}^{3+}$ in iron-deficient environments. The binding constants for $\mathrm{Fe}^{3+}$ can be as high as $10^{52}$ in some cases and their relative affinities for a series of metals is based on size-to-charge ratio. Due to the similarities in size-to-charge ratio between $\mathrm{Fe}^{3+}$ and $\mathrm{Pu}^{4+}$, siderophores can be highly effective sequestering agents for $\mathrm{Pu}^{4+}$ from solution. The siderophore-derived molecule, 1-hydroxy-6-N-octylcarboxamide- $2(1 \mathrm{H})-$ pyridinone (ocyl-1,2-HOPO), has been studied by Dr. Ken Raymond at UC Berkeley for the extraction of plutonium species from acidic media into octanol. We have also studied the extraction behavior of this molecule towards $\mathrm{Pu}^{4+}$ in IL-based separations systems incorporating 
the hydrophobic ILs $\left[\mathrm{C}_{4} \mathrm{mim}\right]\left[\left(\mathrm{SO}_{2} \mathrm{CF}_{3}\right)_{2} \mathrm{~N}\right]$ and $\left[\mathrm{C}_{8} \operatorname{mim}\right]\left[\left(\mathrm{SO}_{2} \mathrm{CF}_{3}\right)_{2} \mathrm{~N}\right]$. The effect of varying alkyl chain length on the IL cation, i.e. cation hydrophobicity, on the extraction efficiency and extraction mechanism was investigated.

Interestingly, the IL with the butyl chain resulted in the extraction of $\mathrm{Pu}^{4+}$ with nearly acid independent behavior, whereas the IL with the octyl chain showed extraction behavior that was strongly acid dependent and most closely paralleled the distribution ratios obtained from the octanol system (Figure 10). In both ILs, however, ligand dependency studies were significantly different from those in octanol. In octanol, four octyl-1,2-HOPO ligands have been shown to coordinate each $\mathrm{Pu}^{4+}$ ion in the extracting phase, whereas in the IL the ligand dependency appeared to drop to $1: 1$, presumably with nitrate anions occupying the coordination sphere of plutonium. Most importantly, however, is the observation that the IL environment can greatly alter the degree to which an extractant molecule interacts with a metal ion, thus supporting the need for more targeted studies aimed at elucidating the nuances of IL coordination chemistry for the ultimate design of better, tailored ILs for application to more complex systems.
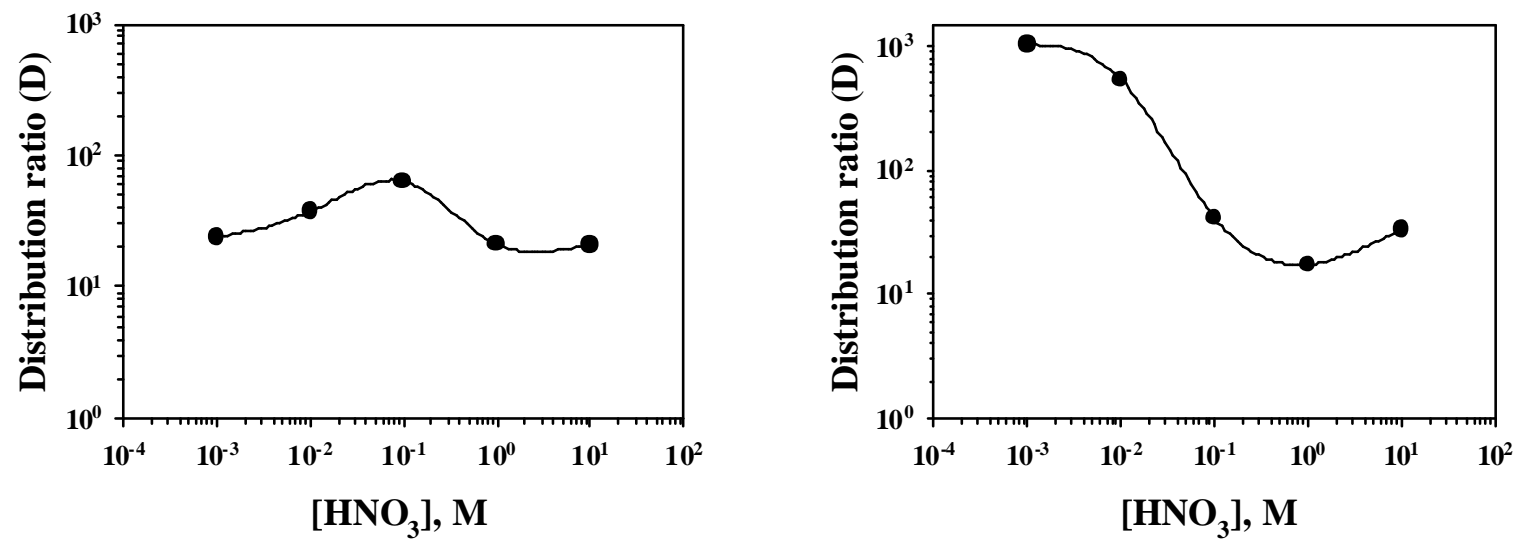

Figure $10 \mathrm{Pu}^{4+}$ distribution ratios for 0.003M octyl-1,2,-HOPO in $\left[\mathrm{C}_{4} \mathrm{mim}\right]\left[\left(\mathrm{SO}_{2} \mathrm{CF}_{3}\right)_{2} \mathrm{~N}\right]$ (left) and $\left[\mathrm{C}_{8} \mathrm{mim}\right]\left[\left(\mathrm{SO}_{2} \mathrm{CF}_{3}\right)_{2} \mathrm{~N}\right]$ versus $\left[\mathrm{HNO}_{3}\right]$.

Summary. Separations systems utilizing ILs as the extracting phase are potentially much more complex that those with simple organic solvents as extracting phases. This arises from the potential for either, or, both cations and anions from the IL to contribute in the extraction processes. In contrast to organic extracting phases, ionic liquids can not necessarily be considered to be passive carrier fluids. solvent extraction, cation, anion, and sacrificial ion exchange mechanisms have been observed, and vary depending on the nature of the ionic liquid components and of the complexants used. recognition and application of this knowledge allows potential control of the complexation and extraction mechanisms.

\section{Develop new Ionic Liquids for TRU separations:}

The success with CMPO as an extractant prompted us to extend the concept of Task Specific Ionic Liquids (TSILs) to actinide separations by including a phosphonamide functional group in the pendant arm of the cation. Not only can extractants be used in IL-based liquid/liquid separations schemes, but extractant functionalities can also be covalently attached to the cation to 
form Task-Specific Ionic Liquids (TSILs). In doing so, one can achieve maximal extractant loading and activity into the extracting phase, thus enhancing metal ion separations processes. In collaboration with Dr. Jim Davis at the University of South Alabama, we have investigated a TSIL containing a CMPO-like phosphonamide functionality.

Partitioning studies were conducted using the TSIL as a $20 \%$ diluent in the non-functionalized base $\mathrm{IL}_{4} \mathrm{mimPF}_{6}$. High distributions for $\mathrm{U}(\mathrm{VI}), \mathrm{Am}(\mathrm{III})$ and $\mathrm{Pu}(\mathrm{IV})$ were observed, but without selectivity (Figure 11). The extraction shows little $\mathrm{pH}$ dependency over a wide $\mathrm{pH}$ range, thus requiring other means to strip the metals. While little optimization has been done using this TSIL, it does illustrate that such materials can be made for TRU partitioning and they can be very efficient. Work is ongoing to develop TSILs with other types of extractant functionalities for TRU separations.
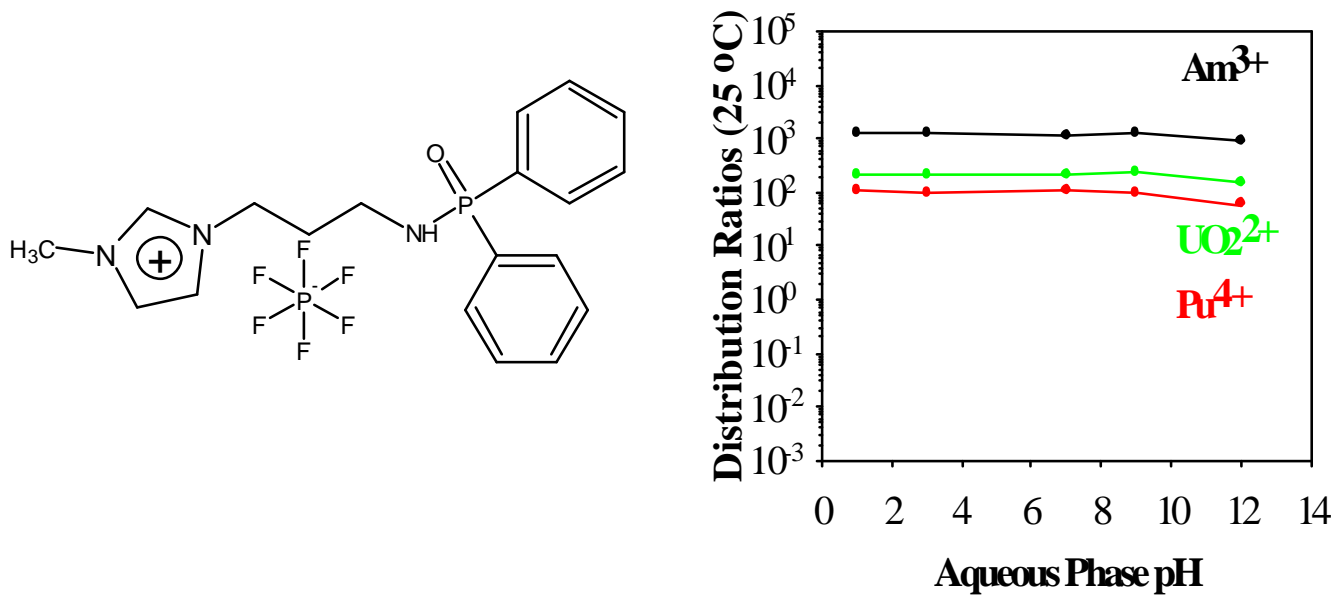

Figure 11. Structure of the $[T S I L]\left[\mathrm{PF}_{6}\right]$ and Ds for partitioning of $\mathrm{Pu}^{4+}, \mathrm{Am}^{3+}$, and $\left[\mathrm{UO}_{2}\right]^{2+}$ from nitric acid solution.

\section{Study the speciation and coordination of TRU elements in both hydrophilic and hydrophobic ionic liquids:}

Speciation and coordination has been studied for major extraction systems: IL/CMPO and IL/Cyanex-272, described above, and have been compared directly with the corresponding metal/complexant systems in dodecane. EXAFS experiments were conducted in collaboration with Dr. Mark Jensen at Argonne National Laboratory.

\subsection{Coordination of $\left[\mathrm{UO}_{2}\right]^{2+}$ in IL/CMPO systems}

The coordination environment of the uranyl nitrate formed with CMPO and TBP in a series of hydrophobic ILs was probed using both UV/Vis spectroscopy and extended X-ray absorption fine structure (EXAFS) spectroscopy. Differences in UV/Vis peak intensity patterns and locations of the uranyl-CMPO complex in ILs and dodecane illustrated their inequivalence. The actual environment around the metal in each instance was explored using EXAFS (Figure 12). Different inner-sphere coordination environments are observed for the uranyl nitrate complexes formed with octyl-phenyl-N,N-diisobutylcarbamoylmethyl-phosphine oxide and tributyl phosphate in dodecane and in the hydrophobic ILs $\left[\mathrm{C}_{4} \mathrm{mim}\right]\left[\mathrm{PF}_{6}\right]$ and $\left[\mathrm{C}_{8} \mathrm{mim}\right]\left[\mathrm{N}\left(\mathrm{SO}_{2} \mathrm{CF}_{3}\right)_{2}\right]$. 
Qualitative differences in the coordination environment of the extracted uranyl species are implied by changes in peak intensity patterns and locations for uranyl UV-visible spectral bands when the solvent is changed. EXAFS data for uranyl complexes in dodecane solutions is consistent with hexagonal bipyramidal coordination and the existence of $\mathrm{UO}_{2}\left(\mathrm{NO}_{3}\right)_{2}(\mathrm{CMPO})_{2}$. In contrast, the complexes formed when uranyl is transferred from aqueous nitric acid solutions into the ILs exhibit an average equatorial coordination number of approx. 4.5. Liquid/liquid extraction results for uranyl in both ionic liquids indicate a net stoichiometry of $\mathrm{UO}_{2}\left(\mathrm{NO}_{3}\right)(\mathrm{CMPO})^{+}$. The concentration of the $\mathrm{IL}$ cation in the aqueous phase increases in proportion to the amount of $\mathrm{UO}_{2}\left(\mathrm{NO}_{3}\right)(\mathrm{CMPO})^{+}$in the IL phase, supporting a predominantly cation exchange mechanism for partitioning in the IL systems

The differences observed between the two types of solvents (ILs and molecular) illustrate the paramount importance of elucidating the unique coordination interactions that occur in the ILs to optimize performance in a variety of tasks.
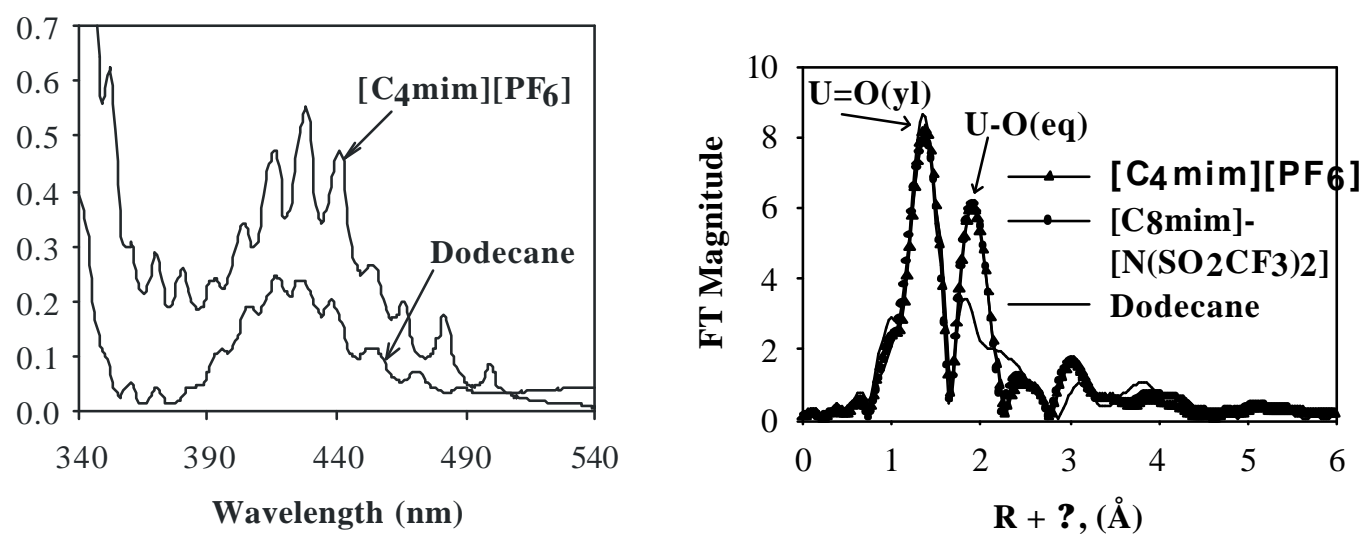

Figure 12. Absorption spectra of dodecane and $\left[\mathrm{C}_{4} \mathrm{mim}\right]\left[\mathrm{PF}_{6}\right]$ solutions containing $0.1 \mathrm{M}$ CMPO and $1 \mathrm{M} \mathrm{TBP}$, after contact with $20 \mathrm{mM} \mathrm{UO}_{2}\left(\mathrm{NO}_{3}\right)_{2}$ in $1 \mathrm{M} \mathrm{HNO}_{3}$. (left) and Fourier transform magnitude of the $k^{3}$ weighted $\mathrm{L}_{3}$ EXAFS of the $\mathrm{UO}_{2}{ }^{2+}$ complexes in dodecane, [C $\left.\mathrm{C}_{4} \mathrm{mim}\right]\left[\mathrm{PF}_{6}\right]$, and $\left[\mathrm{C}_{8} \mathrm{mim}\right]\left[\left(\mathrm{SO}_{2} \mathrm{CF}_{3}\right)_{2} \mathrm{~N}\right.$.].

It was concluded that these results, combined with the previous $\mathrm{Sr}^{2+}$ and $\mathrm{Cs}^{+}$studies indicate that if ILs are to be used as alternatives to traditional organic solvents in liquid/liquid separations of metal salt complexes, greater attention to the design of appropriate ILs and selection of ligand systems will be required. Although ILs have demonstrated their niche in many applications, the observed loss of the $\left[\mathrm{C}_{\mathrm{n}} \mathrm{mim}\right]^{+}$cation to the aqueous phase due to exchange with cationic metal complexes presents unique challenges for future use of ILs in metal ion separations. To prevent a cation exchange mechanism from occurring upon metal ion coordination, there is a need to design more hydrophobic cations for IL composition, possibly through fluorination of the alkyl chain. More research is needed not only in extraction, exchange, and solvation mechanisms, but to realize the true potential of ultimately 'tunable' solvents.

\subsection{Coordination of $\mathrm{Am}^{3+}$ stand-ins, $\mathrm{Nd}^{3+}$ and $\mathrm{Eu}^{3+}$, in IL/Cyanex-272 systems}

Several spectroscopic techniques were implemented to probe the coordination environment of metal ions in the IL in the presence of both Cyanex-272, and a model compound, bis(diethylhexylphosphoric acid), or HDEHP. HDEHP provides a coordination environment that is similar to Cyanex-272. The UV/Vis absorption spectra for $\mathrm{Nd}^{3+}$, a stand-in element for $\mathrm{Am}^{3+}$, 
in both Cyanex-272/[C $\left.{ }_{10} \mathrm{mim}\right]\left[\left(\mathrm{SO}_{3} \mathrm{CF}_{3}\right)_{2} \mathrm{~N}\right]$ and $\mathrm{HDEHP} /$ toluene are shown in Figure 13 . The specta overlap perfectly in the range 560-600 nm, suggesting identical coordination environments in both the IL and toluene.
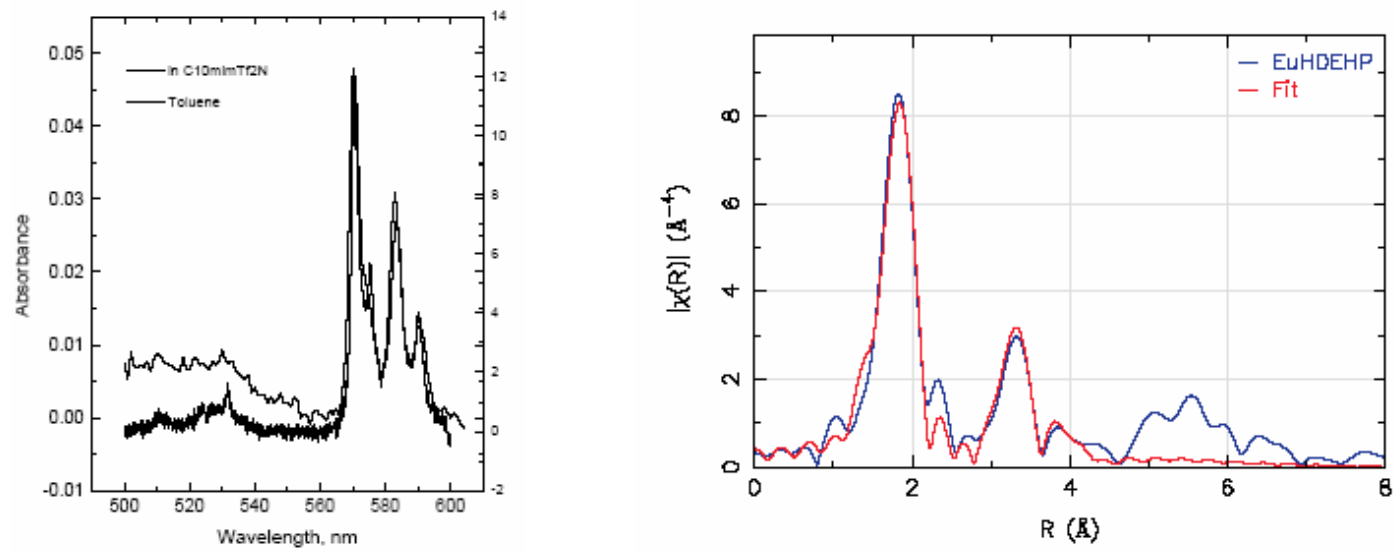

Figure 13 Absorption spectra for $\mathrm{Nd}^{3+}$ in Cyanex 272/[C 10 mim] $\left[\mathrm{Tf}_{2} \mathrm{~N}\right]$ and HDEHP/ toluene (left) and EXAFS data for $\mathrm{Eu}^{3+}$ in $\mathrm{HDEHP} /\left[\mathrm{C}_{10} \mathrm{mim}\right]\left[\mathrm{Tf}_{2} \mathrm{~N}\right]$ (right).

In addition, an analysis of the EXAFS data confirm that the coordination environments in each case are identical. Results obtained from $\mathrm{Eu}^{3+}$ (stand-in for $\mathrm{Am}^{3+}$ ) in $\mathrm{HDEHP} /\left[\mathrm{C}_{10} \mathrm{mim}\right]\left[\left(\mathrm{SO}_{3} \mathrm{CF}_{3}\right)_{2} \mathrm{~N}\right.$ and $\mathrm{Am}^{3+}$ in Cyanex-272/dodecane indicate a coordination number of six in each case with octahedral environments. Further work is being undertaken to probe the nucleation of the complex (i.e., mononuclear vs. dinuclear) as well as aggregation effects of the extractant. In contrast to the results for $\left[\mathrm{UO}_{2}\right]^{2+}$ with $\mathrm{CMPO} / \mathrm{IL}$, this data shows an example where ILs can provide an environment that is identical to molecular solvents, presumably because of dominating coordination effects from the ionized complexant. Thus, once again, it become critical to elucidate the interactions that are important in ILs with regard to extractant binding and coordination. Additionally, investigations with lanthanide analogs as stand-in elements will continue to be important and require further study, especially with regard to macroscopic studies for TRU elements.

\subsection{X-ray structure of a hexavalent dinuclear uranyl nitrate complex in a zwitteronic IL.}

The hydroxyl bridged complex $\left\{\mathrm{UO}_{2}\left(\mathrm{NO}_{3}\right)_{2}(\mathrm{OH})_{2}\left[\mathrm{C}_{1}\right.\right.$ mim] was synthesized by the reaction of $\mathrm{UO}_{2}\left(\mathrm{NO}_{3}\right)_{2} 6 \mathrm{H}_{2} \mathrm{O}$ with 1,3-dimethylimidazolium-2-carboxylate, and the crystal structure (Figure 14) was determined. The uranium atom has a hexagonal bipyramidal of oxygen atoms environment. The diuranium species is formed through $\mathrm{HO}^{-}$bridges which connect the bipyramidal units and the counter ions are 2 ions of 1,3 dimethylimidazolium. Here we have studied the influence of both cation and anion in coordination of the metal when the IL has a reactive site. We will continue to study coordination modes for felements with coordinating IL's such as carboxylates, nitrates, this offering us more understanding of $\mathbb{L}$ 's components effects on metals coordination environment. 


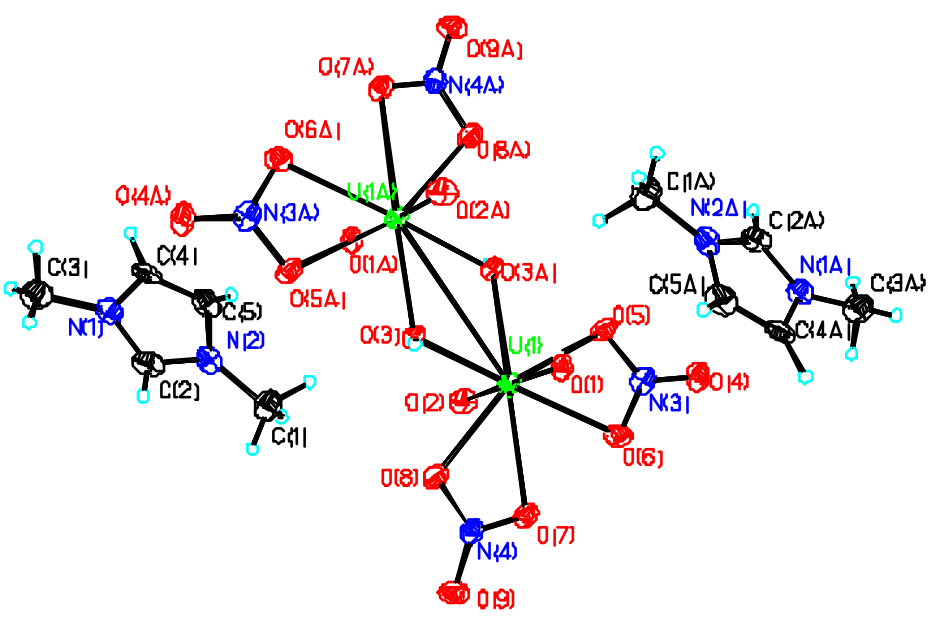

Figure 14. Crystal structure of 1,3-dimethylimidazolium uranylnitrate, isolated by the reaction of 1,3-dimethyl-2-carboxylate IL precursor with uranyl nitrate.

Summary. In the two systems studied in detail by uv/vis spectroscopy and by EXAFS, with CMPO/IL and Cy-272/IL extractant/ionic liquid systems, different metal coordination geometries and numbers were observed with CMPO when compared to the equivalent system with dodecane as solvent, even though there was no evidence for the IL cation or anions participating in the metals first coordination shell. In contrast, the coordination of TRU elements with cyanex-272 revealed comparable coordination environments in the IL and dodecane systems. Strategies to obtain crystalline metal complexes from IL solution are yielding some of the first X-ray structures of imidazolium salts with actinide-containing anions.

4. Investigate how aqueous phase composition affects the liquid/liquid partitioning behavior with particular emphasis on aqueous phases similar to those found in DOE related tank wastes:

While, by definition, only a hydrophobic ionic liquid can form a biphase with water, if the composition of the aqueous phase is changes, then the limits of miscibility and critical points in any phase diagram will also, necessarily, change. We have shown that even a hydrophilic ILs such as 1-butyl-3-methylimidazolium chloride, or $\left[\mathrm{C}_{4} \mathrm{mim}\right] \mathrm{Cl}$, can also be induced to form biphasic systems that are wholly aqueous in nature via the addition of concentrated aqueous solutions of water-structuring salts such as $\mathrm{K}_{3} \mathrm{PO}_{4}$ (Figure 15). We have investigated the range of aqueous biphasic systems (ABS) can be formed ILs and have found that a wide range of IL types, including imidazolium-, pyridinium-, phosphonium-, and ammonium-based salts (Figure 16) can support the formation of biphasic systems, as well as with a variety of inorganic salts including phosphates, carbonates, hydroxides, and some sulfates. By adding 1-butyl-3methylimidazolium chloride, $\left[\mathrm{C}_{4} \mathrm{mim}\right] \mathrm{Cl}$, a hydrophilic ionic liquid (IL), to concentrated solutions of the water-structuring salt, $\mathrm{K}_{3} \mathrm{PO}_{4}$, an aqueous biphasic system (ABS) is produced, forming an upper IL-rich phase and a lower $\mathrm{K}_{3} \mathrm{PO}_{4}$-rich phase, both of which are aqueous. The mutual coexistence curve for the $\left[\mathrm{C}_{4} \mathrm{mim}\right] \mathrm{Cl} / \mathrm{K}_{3} \mathrm{PO}_{4}$ system was determined by the cloud point method at room temperature, and shows that aqueous biphasic systems can be formed over a 
large composition range from monophasic, aqueous solutions of $\left[\mathrm{C}_{4} \mathrm{mim}\right] \mathrm{Cl}$ upon addition of $\mathrm{K}_{3} \mathrm{PO}_{4}$.

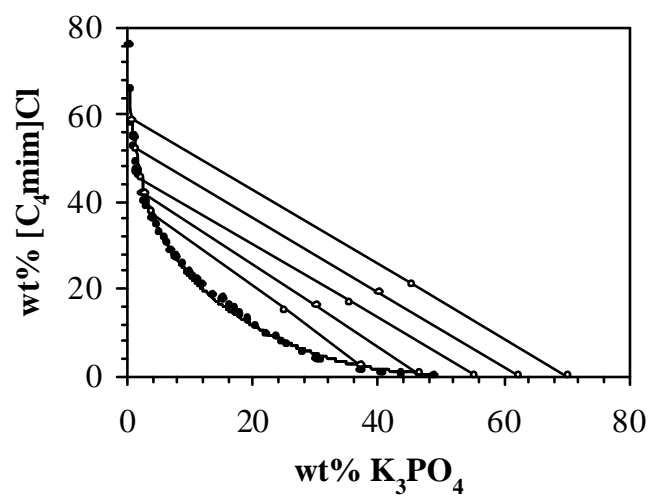

Figure 15. The mutual coexistence curve for the aqueous [ $\left.\mathrm{C}_{4} \mathrm{mim}\right] \mathrm{Cl} / \mathrm{K}_{3} \mathrm{PO}_{4}$ system. System compositions below the coexistence curve are monophasic; compositions above the curve are biphasic. Tie lines (open circles) relate upper and lower phase compositions.

By considering the use of other water-structuring salts to salt-out the IL ions from aqueous solution, a generalization on the formation of $\mathrm{ABS}$ of this type can be made. We have found that a large number of $\mathrm{ABS}$ of $\left[\mathrm{C}_{4} \mathrm{mim}\right] \mathrm{Cl}$ can be formed with a range of kosmotropic salts including $\mathrm{KOH}, \mathrm{K}_{2} \mathrm{CO}_{3}, \mathrm{Na}_{2} \mathrm{HPO}_{4}$, and $\mathrm{Na}_{2} \mathrm{~S}_{2} \mathrm{O}_{3}$. These new ABS can be utilized to recycle or concentrate hydrophilic ILs from aqueous solution, to carry out metathesis in the formation of new IL salts, and for separations, including reactive separations.
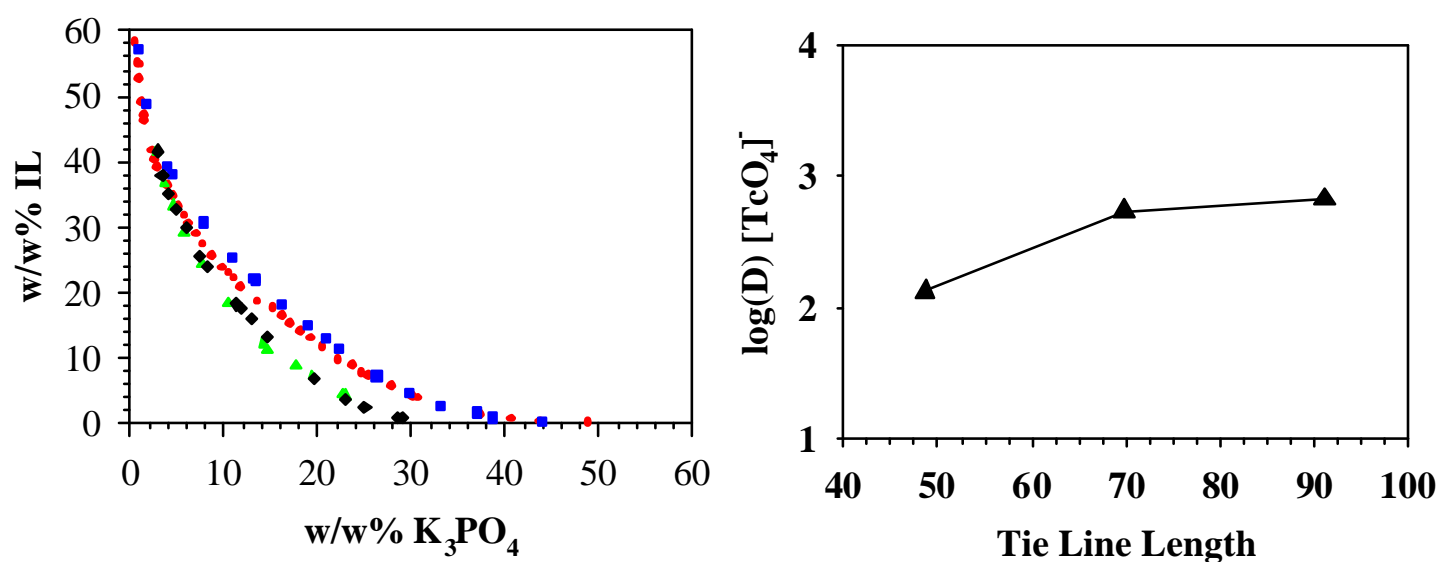

Figure 16 Phase diagram of $\left\{\left[\mathrm{C}_{4} \mathrm{mim}\right] \mathrm{Cl}(?),\left[\mathrm{C}_{4} \mathrm{pyr}\right] \mathrm{Cl}(\mathrm{i}),\left[\left(\mathrm{C}_{4}\right)_{4} \mathrm{~N}\right] \mathrm{Cl}(?),\left[\left(\mathrm{C}_{4}\right)_{4} \mathrm{P}\right] \mathrm{Cl}\right.$ (? ) $\} / K_{3} \mathrm{PO}_{4}$ aqueous biphasic system. Points above the curve are biphasic while those below the curve are monophasic (left) and Distribution of $\mathrm{TcO}_{4}^{-}$to IL-rich phase of IL-based ABS as a function of tie line length (increasing phase divergence) (right).

It is important to note that many of these inorganic salts are present in large amounts in nuclear tank wastes. As a result, these salt-salt biphasic systems are excellent models to critically investigate the behavior and sustainability of ILs with regard to stability and ion exchange under tank waste conditions. For example, it was found that $\mathrm{TcO}_{4}{ }^{-}$will quantitatively partition from a 
concentrated $\mathrm{K}_{3} \mathrm{PO}_{4}$ solution to the IL-rich phase without the need for an extractant (Figure 8x). This offers the potential to remove $\mathrm{TcO}_{4}{ }^{-}$from tank waste using solid-supported IL technology. In addition, further studies of the role of the IL anion and cation in these systems will aid in developing new ILs that are better suited for tank waste applications such as actinide and fission product separations.

Summary. With recognition that 1,3-dialkylimidazolium-based ILs are unsuitable for study under caustic, high $\mathrm{pH}$, conditions a wider range of ILs with increased $\mathrm{pH}$ stability is needed. Significantly, while only a limited number of hydrophobic ILs are known that form biphases with water, when high ionic strength aqueous phases, such as are present in the HLW streams, a much wider range of ILs are capable of sustaining liquid-liquid biphase formations, we term these salt-salt systems, and can be applied to extraction and separations systems. Notably, we have shown that $\left[\mathrm{TcO}_{4}\right]^{-}$partitions to the organic IL phase of simple salt-salt biphasic systems such as these with distribution ratios between 100-800 in the absence of any additional extractants.

\section{Determine the stability of ionic liquids to thermolysis and radiolysis:}

A recent report in the literature indicates that due to the ability of aromatic rings to absorb energy, radiolysis of $\left[\mathrm{C}_{\mathrm{n}} \mathrm{mim}\right]^{+}$cations does not appear to present a problem (D. Allen, et. al. Green Chem. 2002, 4, 152-158). The preliminary assessment of radiation stability of $\left[\mathrm{C}_{\mathrm{n}} \mathrm{mim}\right] \mathrm{Cl}$ and $\left[\mathrm{C}_{4} \mathrm{mim}\right]\left[\mathrm{NO}_{3}\right]$ ILs to ?, ?, and ? radiation indicated no significant decomposition. The $\left[\mathrm{C}_{\mathrm{n}} \mathrm{mim}\right] \mathrm{Cl}$ and $\left[\mathrm{C}_{4} \mathrm{mim}\right]\left[\mathrm{NO}_{3}\right]$ ILs appeared to be much more stable than TBP/kerosene mixtures after similar irradiation conditions. Additional ILs and process conditions need to be investigated.

6. Investigate the unique heat transfer properties of ionic liquids for use in other processing steps:

\subsection{Thermophysical Properties of ILs}

The General trends in the physical properties of ILs are reasonably well established. For example, variation in the melting points of alkyl-methylimidazolium salts with alkyl-chain length and thermal decomposition temperatures (under dynamic heating) with anion type are shown in Figure 17. The general trends are for halide salts to be least stable, and bistrifylimide ionic liquids to have the greatest thermal stability for any given cation.

\subsection{Determination of Heat Capacities}

The thermophysical properties of a key set of ILs have been investigated. Heat capacity data have been determined as a function of temperature (Figure 18) and have been correlated with data on changes in density with temperature in order to calculate volumetric heat capacities and thermal energy storage potentials of the ILs across a wide temperature range. This data is of value for chemical and process engineering for thermodynamic calculations and reactor designs, and also show that ILs have similar thermal properties to commercial synthetic heat transfer fluids (such as diphenylethers and polysiloxane fluids, Figure 19). For all the common ILs screened, the specific heat capacities were between $1.17-1.80 \mathrm{~J} \mathrm{~g}^{-1} \mathrm{~K}^{-1}$ at $100{ }^{\circ} \mathrm{C}$, and increased linearly with temperature in the liquid region studied. 

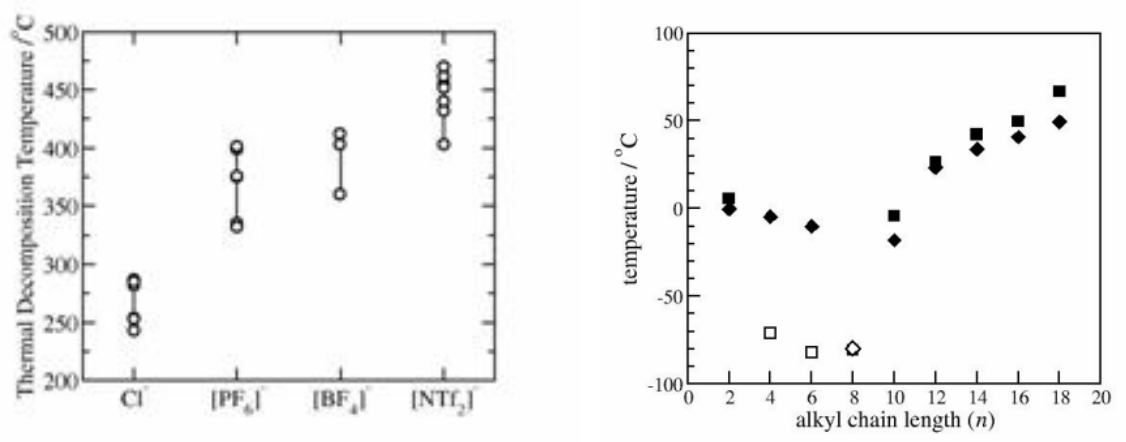

Figure 17. Decomposition temperatures (dynamic) for a range of ILs, ranked by anion type (left) and melting points and glass transitions (open symbols) for [ $\mathrm{C}_{n}$ mim] ILs with $\left[\mathrm{BF}_{4}\right]^{-}$and $\left[\mathrm{NTf}_{2}\right]^{-}$ anions (right).

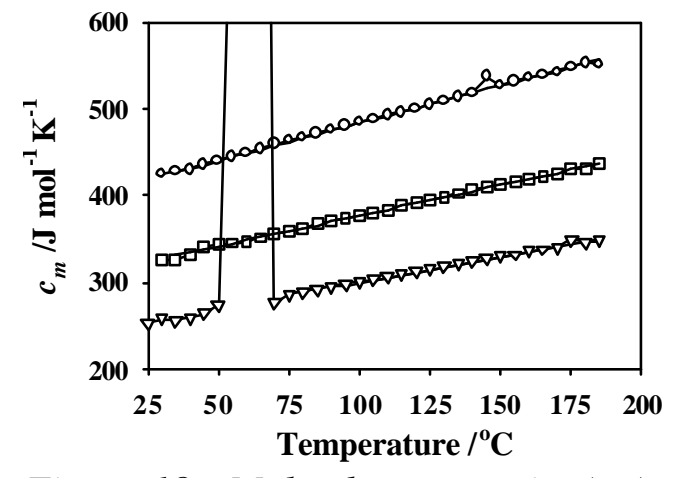

Figure 18. Molar heat capacity $\left(c_{m}\right)$ as a function of temperature for three $\left[\mathrm{PF}_{6}\right]^{-}$ ILs $\left(\left[\mathrm{C}_{2} \mathrm{mim}\right]^{+} \quad(?), \quad\left[\mathrm{C}_{4} \mathrm{mim}\right]^{+} \quad(?)\right.$, [C $\left._{6} \mathrm{mim}\right]^{+}($?).

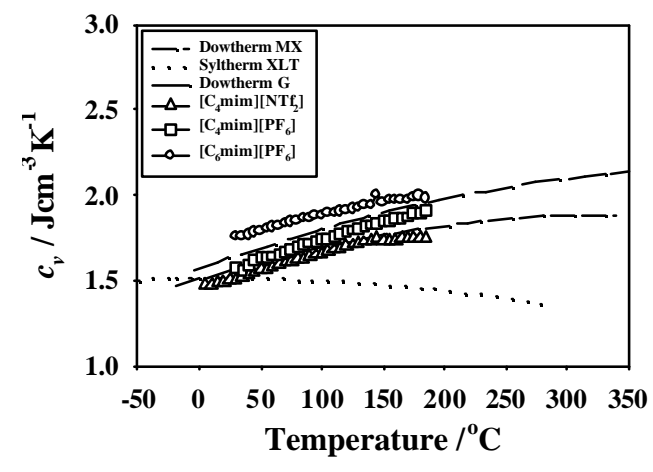

Figure 19. Comparison of volumetric heat capacity with temperature for the three ILs and some commercial thermal fluids.

7. Publications and Presentations at Meetings Acknowledging DOE support from the Current Project Period:

\subsection{Refereed Publications}

1. Gutowski, K. E.; Bridges, N. J.; Cocalia, V. A.; Spear, S. K.; Visser, A. E.; Holbrey, J. D.; Davis Jr., J. H.; Rogers, R. D. "Ionic Liquid Technologies for Utilization in Nuclear-based Separations," in Ionic Liquids III, Fundaments, Progress, Challenges and Opportunities, Rogers, R. D.; Seddon K. R., Eds, ACS Symposium Series, 901, in press.

2. Holbrey, J. D. "Industrial Applications of Ionic Liquids" Chim. Oggi, 2004, 22, 35-37.

3. Luo, H.; Dai, S.; Bonnesen, P. V.; A. C. Buchanan, III, Holbrey, J. D.; Bridges, N. J.; and Rodger, R. D. "Extraction of Cesium Ions from Aqueous Solutions Using Calix[4]arenebis(tert-octylbenzo-crown-6) in Ionic Liquids" Anal. Chem., 2004, 76, 3078-3083.

4. Rogers, R. D.; Gutowski, K. E.; Griffin, S. T.; Holbrey, J. D. "Aqueous biphasic systems based on salting-out polyethylene glycol or ionic liquid solutions: strategies for actinide or fission product separations. Preprints of Extended Abstracts presented at the ACS National 
Meeting, American Chemical Society, Division of Environmental Chemistry 2004, 44, 403407.

5. Visser, A. E.; Rogers, R. D. "Actinide Chemistry in Novel Solvent Media: Room Temperature Ionic Liquids" In Molten Salts XIII; Delong, H. C., Bradshaw, R. W., Matsunaga, M., Stafford, G. R., Trulove, P. C., Eds.; The Electrochemical Society: Pennington, NJ, 2002; pp 516-529.

6. Visser, A. E.; Jensen, M. P.; Laszak, I.; Nash, K.L.; Choppin, G. R.; Rogers, R. D. "Uranyl Coordination Environment in Hydrophobic Ionic Liquids: An In Situ Investigation," Inorg. Chem., 2003, 42, 2197-2199.

7. Visser, A. E.; Rogers, R. D. "Room Temperature Ionic Liquids: New Solvents for f-Element Separations and Associated Solution Chemistry," J. Solid State Chem. 2003, 171, 109-113.

8. Gutowski, K. E.; Broker, G. A.; Willauer, H. D.; Huddleston, J. G.; Swatloski, R. P.; Holbrey, J. H. "Controlling the Aqueous Miscibility of Ionic Liquids: Aqueous Biphasic Systems of Water-Miscible Ionic Liquids and Water-Structuring Salts for Recycle, Metathesis, and Separations," J. Am. Chem. Soc. 2003, 125, 6632-6633.

9. Holbrey, J. D.; Reichert, W. M.; Reddy, R. G.; Rogers, R. D. "Heat Capacities of Ionic Liquids and Their Applications as Thermal Fluids" In Ionic Liquids as Green Solvents: Progress and Prospects; Seddon, K. R., Rogers, R. D., Eds.; ACS Symposium Series 856, 2003; pp121-133.

10. Holbrey, J. D.; Visser, A. E. Spear, S. K.; Reichert, W. M.; Swatloski, R. P.; Broker, G. A.; Rogers, R. D. "Mercury(II) Partitioning from Aqueous Solutions with a New, Hydrophobic Ethylene-Glycol Functionalized Bis(methylimidazolium) Ionic Liquid," Green Chem. 2003, 5, 129-135.

\subsection{Thesis Completed}

1. A. E. Visser, "Metal Ion Separations in Aqueous Biphasic Systems and Room Temperature Ionic Liquids," Ph.D., The University of Alabama, 2002.

\subsection{Presentations before National and International Meetings}

1. Rogers, R. D.; Visser, A .E.; Davis, J. H., Jr. "Actinide Separations Utilizing Room Temperature Ionic Liquids," Presented by A. E. Visser at the Actinides-2001 International Conference, 2001, Hayama, Japan, Abstract 4010.

2. Visser, A. E.; Jensen, M. P.; Nash, K. L.; Rogers, R. D. "Investigation of Actinide Complexation and Solvation in Room Temperature Ionic Liquids, " Presented by A. E. Visser at the Actinides-2001 International Conference, 2001, Hayama, Japan, Abstract 2015.

3. Visser, A .E.; Swatloski, R. P.; Reichert, W. M.; Rogers, R. D. "Actinide Separations in Room-Temperature Ionic Liquids," Presented by A. E. Visser before the $12^{\text {th }}$ Symposium on Separations Science and Technology for Energy Applications, 2001, Gatlinburg, TN, Abstract Book p 88.

4. Swatloski, R. P.; Visser, A. E.; Davis, J. H., Jr.; Rogers, R. D. "Actinides in Room Temperature Ionic Liquids; Old Elements - New Solvents," Presented by R. P. Swatloski before the $223^{\text {rd }}$ ACS National Meeting, 2002, Orlando, FL, Abstract NUCL 132.

5. Rogers, R. D.; Visser, A. E.; Davis, J. H., Jr.; Koval, C.; DuBois, D. L.; Scovazzo, P.; Noble, R. D. "Choosing Ionic Liquids for Supported Ionic Liquid Membranes," Presented by R. D. 
Rogers before the $223^{\text {rd }}$ ACS National Meeting, 2002, Orlando, FL, Abstract I\&EC 128. (Invited Symposium Presentation)

6. Rogers, R. D.; Visser, A. E. "Actinide Chemistry in Novel Solvent Media: Room Temperature Ionic Liquids," Presented by R. D. Rogers before the $13^{\text {th }}$ International Symposium on Molten Salts, part of the $201^{\text {st }}$ National Meeting of the Electrochemical Society, 2002, Philadelphia, PA, Abstract 1446. (Invited Presentation)

7. Rogers, R. D.; Visser, A. E. "Room Temperature Ionic Liquids: New Solvents for f-element Separations and Associated Solution Chemistry," Presented by R. D. Rogers before the $23^{\text {rd }}$ Rare Earth Research Conference, 2002, Davis, CA, Abstract OSE-1-05.

8. Visser, A. E.; Jensen, M. P.; Nash, K. L.; Rogers, R. D. "An Investigation of Actinide and Fission Product Extraction in Room Temperature Ionic Liquids: Liquid/Liquid Separations and In-Situ Solution Analysis," Presented by A. E. Visser before the $224^{\text {th }}$ ACS National Meeting, 2002, Boston, MA, Abstract I\&EC 88.

9. Rogers, R. D.; Holbrey, J. D.; Visser, A. E. "Application of Task Specific Ionic Liquids to the Extraction of $\mathrm{Hg}^{2+}$ and Actinides," Presented by R. D. Rogers before the $54^{\text {th }}$ Southeast Regional ACS Meeting, 2002, Charleston, SC, Abstract 575. (Invited Symposium Presentation).

10. Rogers, R. D. "A New Class of Solvents for TRU Dissolution and Separation: Ionic Liquids," Presented by R. D. Rogers before the Department of Energy Environmental Management Sciences Program Principal Investigators Workshop, 2003, Richland, WA, no abstract.

11. Rogers, R. D.; Holbrey, J. D.; Spear, S. K.; Gutowski, K. E.; Bridges, N. J.; Cocalia, V. A.; Swatloski, R. P. "Application of Ionic Liquid Technologies to Nuclear Separations," Presented by R. D. Rogers before the $27^{\text {th }}$ Actinide Separations Conference, 2003, Lemont, IL, Abstract Book p 12.

12. Cocalia, V. A.; Brid ges, N. J.; Griffin, S. T.; Spear, S. K.; Rogers, R. D. "Uranyl Extraction using Cyanex-272 in 1-Decyl-3-methylimidazolium Bis(trifluoromethanesulfonyl)imide," Presented by V. A. Cocalia before the $27^{\text {th }}$ Actinide Separations Conference, 2003, Lemont, IL, Abstract Book p 36.

13. Rogers, R. D.; Holbrey, J. D.; Spear, S. K.; Gutowski, K. E.; Bridges, N. J.; Cocalia, V. A.; Swatloski, R. P. "Application of Ionic Liquid Technologies to Nuclear Separations," Presented by R. D. Rogers before the ACS National Meeting, Sept. 7-11, 2003, New York, NY, NUCL Abstract Book p 40.

14. Gutowski, K. E.; Broker, G. A.; Willauer, H. D.; Huddleston, J. G.; Swatloski, R. P.; Holbrey, J. D.; Rogers, R. D. "Controlling the Aqueous Miscibility of Hydrophilic Ionic Liquids Via the Addition of Water-Structuring Salts," Presented by K. E. Gutowski before the $13^{\text {th }}$ Symposium on Separation Science and Technology, Oct. 27-30, 2003, Gatlinburg, TN, Abstract Book p 68.

15. Bridges, N. J.; Rogers, R. D. "Comparative Studies of Cyanex-923 in Ionic Liquids Versus Traditional Organic Solvents," Presented by N. J. Bridges before the $13^{\text {th }}$ Symposium on Separation Science and Technology, Oct. 27-30, 2003, Gatlinburg, TN, Abstract Book p 79.

16. Cocalia, V. A.; Bridges, N. J.; Griffin, S. T.; Spear, S. K.; Rogers, R. D.; "Actinide Partitioning Using the Traditional Extractant Cyanex 272 in a Room Temperature Ionic Liquid as a Novel Medium for Liquid/Liquid Extraction," Presented by V. A. Cocalia before the $13^{\text {th }}$ Symposium on Separation Science and Technology, Oct. 27-30, 2003, Gatlinburg, TN, Abstract Book p 80. 
17. Gutowski, K. E.; Holbrey, J. D.; Spear, S. K.; Bridges, N. J.; Rogers, R. D. “Approaches to Nuclear Separations Using Room Temperature Ionic Liquids" Presented by K. E. Gutowski before the American Nuclear Society Global 2003 Meeting, Nov. 16-20, 2003, New Orleans, LA, abstract on CD only.

18. Reichert, W. M.; Holbrey, J. D.; Griffin, S. T.; Cocalia, V. A.; Bridges, N. J.; Chambers, J.; Rogers, R. D. "Task Specific Ionic Liquids that Incorporate Poly(ethylene glycol) Functionality for the Extraction of Metal Ions Presented by W. M. Reichert before the ACS National Meeting, Mar. 28- Apr. 1, 2004, Anaheim, CA, IEC-228.

19. Rogers, R. D.; Bridges, N. J.; Holbrey, J. D.; Luo, H.; Dai, S.; Bonnesen, P. V. "The Role of Ion Exchange versus Solvent Extraction Processes in Metal Ion Partitioning in Ionic Liquid/Aqueous Systems: Cesium Extractions with Calix[4]arene-bis(tert-octylbenzo-crown6) in Imidazolium Bistrifylimide Ionic Liquids," Presented by R. D. Rogers before the ACS National Meeting, Mar. 28- Apr. 1, 2004, Anaheim, CA, IEC-227. 